\title{
TRAJETÓRIA DE MODERNIZAÇÃO DA AGROPECUÁRIA MINEIRA NO PERÍODO DE 1996 A 2006
}

\author{
Samuel Alex Coelho Campos* \\ Matheus Wemerson Gomes Pereira ${ }^{\dagger}$ \\ Erly Cardoso TeIXeira $\ddagger$
}

\begin{abstract}
Resumo
O presente trabalho analisou as trajetórias tecnológicas agropecuárias das microrregiões mineiras entre os anos de 1996 e 2006, identificandoas quanto a tamanho e escala, modernização, tecnologia, produtividade, adoção de práticas de conservação e as relações entre essas dimensões. Para isso, utilizou-se a Análise Fatorial Múltipla (AFM) e agrupamentos. Destacou-se a reduzida capacidade dos estabelecimentos em absorver e fazer uso efetivo dessas novas tecnologias, bem como a relação inversa entre a dimensão para o meio ambiente e para a adoção tecnológica, que pode ser explicada pelo custo de oportunidade do capital.
\end{abstract}

Palavras-chave: agropecuária; modernização tecnológica; produtividade da terra e do trabalho; análise fatorial múltipla; microrregiões mineiras.

\begin{abstract}
The aim of this study is to examine the agriculture technological trajectories of micro-regions of Minas Gerais state from 1996 to 2006. The study identified five dimensions and its interrelation: size and scale, modernization, technology, productivity and adoption of conservation practices. Multiple Factor Analysis (MFA) and clusters Analysis were applied. It was highlighted the reduced ability of farmers to absorb and use new technologies, as well as the inverse relationship between environment dimension and technological adoption, which can be explained by opportunity cost of capital.
\end{abstract}

Keywords: Agriculture; Minas Gerais; technological modernization; land and labor productivity; multiple factorial analysis.

JEL classification: C10, C40, Q18, Q19.

DOI: http://dx.doi.org/10.1590/1413-8050/ea115282

\footnotetext{
* Universidade de São Paulo. E-mail: s.alex.coelho@gmail.com

† Universidade Federal de Mato Grosso do Sul. E-mail: matheuswgp@yahoo.com.br

‡ Universidade Federal de Viçosa. E-mail: teixeira@ufv.br
} 


\section{Introdução}

A partir da década de 1990, a agropecuária brasileira sofreu diversos efeitos das políticas macroeconômicas e de mudanças em instrumentos da política agrícola. Essas alterações atingiram de forma não uniforme os produtos agropecuários, beneficiando alguns e prejudicando a produção de outros. Assim, as alterações da década surtiram diversos efeitos entre as regiões, beneficiando algumas regiões e prejudicando a outras, em razão do tipo de produtos agropecuários ao qual cada região se dedicou ou se especializou.

Para os produtos exportáveis, houve um aumento da área colhida, da produção e produtividade, ao passo que os produtos importáveis ou não comercializáveis foram prejudicados, reduzindo a produção e área plantada, e aumentando a importação (Helfand \& Resende 2001). Essa modificação foi resultado da eliminação de impostos e restrições à exportação e às importações, redução do crédito rural com focalização nos pequenos produtores familiares, facilitação do acesso ao capital internacional com taxas de juros menores, ciclos de preços dos ativos agrícolas advindos dos diversos planos de estabilização implantados até o Plano Real, incentivo à utilização de insumos poupadores de terra e mão de obra, como fertilizantes e tratores, e concentração dos estabelecimentos rurais agropecuários, conforme apontado por Freitas et al. (2004).

Esse processo incentivou e privilegiou a produção agropecuária em grandes estabelecimentos para a exportação, baseado em ganhos de escala, produtividade e eficiência (com a saída dos produtores menos eficientes e com dificuldades de competir nesse novo cenário de redução de custos) e no uso intensivo de tecnologias, marginalizando os produtores com pequena escala de produção, que não dispunham de capital e tinham pouco acesso às linhas de crédito por limitações constitucionais (posse precária da terra por assentados) e falta de garantias e de informação para o uso dessas tecnologias.

Além disso, a política do governo reduziu sua atuação, almejando contornar as falhas de mercado, apoiando os pequenos produtores familiares, com a criação do Pronaf, abandonando a política de preços mínimos (PPM) como parâmetro para a política de garantia de preços e permitindo o acesso à PPM apenas àqueles que utilizaram o crédito oficial, incentivou a estocagem privada, substituiu o Empréstimo do Governo Federal (EGF) pelos contratos de opção de venda e pelo EGF sem opção de venda.

Essas alterações influenciaram a trajetória de desenvolvimento da agropecuária mineira, a adoção de tecnologias e modernização, que se processou de forma desigual em razão da heterogeneidade econômica, social e das próprias atividades agropecuárias às quais as regiões se dedicavam.

Essa heterogeneidade pode ser percebida entre as mesorregiões mineiras, segundo Carneiro \& Fontes (2005), com regiões de agricultura mecanizada e moderna com produção para exportação em propriedades médias a grandes (Noroeste, Triângulo Mineiro/Alto Paranaíba e Oeste), regiões de elevada pobreza e agricultura de subsistência (Norte, Jequitinhonha), regiões com elevada diversificação (Sul/Sudoeste), de pecuária extensiva (Vale do Mucuri) e outras regiões de baixa concentração da terra e pequenas propriedades rurais (Zona da Mata).

A agropecuária mineira nos anos de 1990, segundo Cruz (2007), reduziu sua participação no PIB estadual pelo baixo crescimento dos preços médios no estado em relação à média nacional. Apesar disso, a agropecuária mineira apresentou as maiores taxas de crescimento da produção agrícola entre os es- 
tados brasileiros. O crescimento da produção agrícola mineira, ao contrário de estados como Mato Grosso do Sul, Mato Grosso e Tocantins, ocorreu não em função da expansão da fronteira agrícola, mas em função de ganhos de produtividade.

Nesse contexto de mudanças econômicas e políticas, diversos estudos analisaram o comportamento da agropecuária no período de 1980 e/ou 1985 a 1995/96, tanto a nível estadual como nacional (Meyer 1997, Meyer \& Braga 1998, Helfand \& Resende 2001, Kageyama \& Leone 2002, Souza \& Lima 2003, Ferreira Júnior et al. 2004, Llanillo et al. 2006, Silva et al. 2008, Gasques et al. 2010). O trabalho de Kageyama \& Leone (2002) identificou a trajetória da modernização e do emprego agrícola para os estados brasileiros utilizando dados do Censo Agropecuário de 1985 e 1995/96 e a Análise Fatorial Múltipla, objetivando a demonstrar como essa metodologia poderia ser aplicada em estudos que tratem de muitas variáveis na análise, como a modernização.

Analisando a evolução da modernização por unidades da federação entre 1970 a 1995, utilizando a análise fatorial e cluster, e dados do censo agropecuário, Souza \& Lima (2003) identificaram que a intensidade de modernização foi significativamente diferente entre os estados quanto à velocidade da modernização, que, entretanto, não teria sido interrompida com a queda no financiamento e investimento no setor.

Ao nível estadual, Llanillo et al. (2006), utilizando a análise multivariada e dados do Censo Agropecuário de 1995/96, analisaram a regionalização da agropecuária paranaense e classificaram os municípios em 11 padrões diferenciados, desde agropecuária de baixa modernização, passando pela agricultura familiar de baixa intensidade à familiar moderna e especializada na produção de alguns produtos, como bovinos, café, lavouras permanentes etc. Para o estado de Minas Gerais, Silva et al. (2008) analisaram o processo de modernização agropecuária para as microrregiões na década de 1990 utilizando a análise multivariada, como adotado por Souza \& Lima (2003) e Llanillo et al. (2006), e dados do Censo Demográfico de 2000 e Agropecuário 1995/96. Os resultados indicaram comportamento diferenciado entre as microrregiões, com uma agropecuária mais dinâmica, de maior lucratividade e maior progresso técnico no Oeste do estado e agropecuária mais atrasada e tradicional no Leste de Minas Gerais.

Já o estudo de Gasques et al. (2010) analisou o comportamento da produtividade da agricultura brasileira entre os anos 1970 e 2006. Para isso, os autores usaram índices de produtividade total dos fatores, que indicaram uma tendência geral para a diversificação da agricultura, destacando que os estados de Espírito Santo e Minas Gerais apresentaram produtividade superior à média brasileira nos anos de 1996 a 2006. A pecuária se manteve entre os 10 principais produtos no valor da produção agropecuária. Alguns produtos comumente associados à pequena produção ou à produção familiar perderam importância, como feijão e mandioca, e outros tiveram sua participação aumentada, como a cana-de-açúcar. Destaca-se também a elevação da importância no uso de insumos tidos como modernos, como adubos e corretivos, energia elétrica e óleo diesel, estes últimos associados à maior mecanização. Assim, uma rápida observação indica um comportamento de modernização intensivo em capital, voltado para culturas de exportação ou de grande escala, como a cana-de-açúcar.

Nesse sentido, torna-se oportuno investigar as trajetórias dos sistemas produtivos mineiros quanto ao desenvolvimento regional agropecuário, incluindo 
variáveis que reflitam a modernização, a produtividade da terra e do trabalho, a escala e tamanho dos estabelecimentos e o meio ambiente em um período mais recente (1996 e 2006), objetivando determinar e analisar as trajetórias tecnológicas das microrregiões mineiras. Especificamente, foram determinadas as trajetórias da agropecuária quanto a tamanho e escala, tecnologia, modernização, produtividade e utilização de boas práticas agrícolas de produção, classificando as microrregiões de acordo com as trajetórias.

Assim, este artigo contribui para o tema em vários aspectos: incorpora o meio ambiente, analisando a trajetória das práticas de conservação pelos estabelecimentos agropecuários e suas inter-relações com a modernização da agropecuária mineira; utiliza a Análise Fatorial Múltipla, que, ao contrário da Análise Fatorial "Clássica", permite mensurar a trajetória de modernização técnica de forma não viesada, ponderando apropriadamente os diferentes grupos de variáveis, de forma a evitar que um só grupo determine a direção principal da análise fatorial global; e atualiza o debate e a análise da modernização na agropecuária e sua seletividade e não homogeneidade.

\section{Metodologia}

O estudo da modernização da agropecuária é um processo complexo, uma vez que considera inúmeras variáveis, como componentes técnicos, transações monetárias e mudanças no mercado de trabalho. Assim, a análise fatorial múltipla é utilizada como forma de "resumir" o comportamento das diversas variáveis relacionadas ao processo de modernização da agropecuária mineira em um número menor de variáveis e permitir sua interpretação e análise. Posteriormente, os escores fatoriais foram utilizados na formação de grupos de microrregiões com comportamento semelhante quanto á trajetória.

\subsection{Método de Análise Fatorial Múltipla (AFM)}

O método analítico escolhido para o desenvolvimento do trabalho é conhecido como Análise Fatorial Múltipla (AFM), que consiste em analisar as observações descritas por vários "blocos" ou conjuntos de variáveis. A AFM é realizada em duas etapas. Primeiramente, emprega-se a análise de componentes principais (ACPs) em cada conjunto de dados, os quais são normalizados (i.e., ponderados), dividindo todos os seus elementos pela raiz quadrada do primeiro autovalor obtido da ACP. Em segundo lugar, os conjuntos de dados normalizados são agrupados para formar uma única matriz de ACP global. O método garante que a importância relativa dos grupos seja equilibrada, de modo que nenhum deles possa determinar por si só a primeira direção principal da análise global. Os conjuntos de dados individuais são então projetados para a análise global, a fim de analisar comunalidades e discrepâncias (Escofier \& Pagès 1984).

Segundo Escofier \& Pagès (1984), esse método pode ser muito útil para análise de problemas em que é possível identificar vários grupos de variáveis em períodos de tempo diferentes, como no caso da presente análise.

Neste estudo, os dados serão organizados em grupos de variáveis que estejam associadas à tecnologia, ao tamanho, à modernização, ao meio ambiente e à produtividade dos estabelecimentos. Considere que esses grupos formem matrizes de dados X1, X2, X3, X4 e X5, respectivamente. 
Na Análise Fatorial Múltipla, primeiramente (ABDI; VALENTIN, 2007) é aplicada a Análise de Componentes Principais (PCA) e calculados os autovalores para cada grupo de dados (cada matriz de dados), então, o primeiro valor singular ${ }^{1}$ de cada grupo é utilizado para normalizar a matriz de dados:

$$
Z_{i}=1 \varphi_{i}^{-1} X_{i}
$$

com $i=1,2, \ldots, 5$ em que $Z_{i}, 1 \varphi_{i}^{-1}$ e $X_{i}$ são a matriz normalizada, o primeiro valor singular e a matriz original de dados, respectivamente, do grupo $i$.

As matrizes $Z_{i}$ padronizadas são então concentradas em uma única matriz $Z$ :

$$
Z=\left[Z_{1} Z_{2} Z_{3} Z_{4} Z_{5}\right]
$$

E aplicada a PCA da forma usual a essa matriz de dados padronizada:

$$
Z=U \Delta V^{T} \operatorname{com} U U^{T}=V^{T} V=I
$$

em que $U$ e $V$ são os vetores singulares esquerdo e direito do vetor $Z$, e $\Delta$ é a matriz diagonal de valores singulares ou autovalor. Os autovalores ou raízes características são calculados por:

$$
\Lambda=\Delta^{2}
$$

Os escores fatoriais globais são obtidos por:

$$
F=M^{\frac{-1}{2}} U \Delta
$$

Permitindo uma análise do comportamento global do conjunto de dados. Para analisar cada grupo de dados, reescreve-se 5 como:

$$
F=M^{\frac{-1}{2}} U \Delta=\left(Z Z^{T}\right)^{*}\left(M^{\frac{-1}{2}} U \Delta^{\frac{-1}{2}}\right)=\left(Z Z^{T}\right)^{*} P
$$

em que $P$ é a matriz de projeção que transforma a matriz $Z Z^{T}$ nos escores fatoriais. Assim, os escores fatoriais de cada grupo podem ser calculados:

$$
F_{i}=T^{*}\left(Z_{i} Z_{i}^{T}\right)^{*} P
$$

em que $F_{i}$ são os escores fatoriais do grupo $i$, e $T$ é o número de grupos da análise. No presente estudo, $\mathrm{T}=5$, sendo 4 (quatro) os grupos ativos.

\subsection{Variáveis e tratamento dos dados}

Para a análise empírica foram utilizados dados secundários, tendo como fonte os Censos Agropecuários referentes aos períodos de 1995/96 e 2006 (IBGE $2010 \mathrm{a}, \mathrm{b})$. Os dados referentes a preços e outros valores foram deflacionados pelo IGP (FGV 2010) para o período de julho de 1996. A escolha das variáveis e dos grupos está associada aos objetivos do estudo, sendo que variáveis semelhantes foram utilizadas por Meyer (1997), Meyer \& Braga (1998), Kageyama \& Leone (2002), Souza \& Lima (2003). As variáveis utilizadas foram limitadas pela disponibilidade de dados do Censo Agropecuário de 1995/96.

\footnotetext{
${ }^{1} \mathrm{O}$ valor singular é calculado por meio da raiz quadrada do eigenvalue.
} 
A modernização da agropecuária compreende uma grande diversidade de variáveis relacionadas, assim, foram criados cinco grupos, que organizam essas variáveis de acordo com a dimensão representada. Posteriormente, foi aplicada a Análise Fatorial Múltipla a esses grupos, como forma de resumir a informação dessas variáveis em apenas cinco, representadas pelos grupos.

As variáveis foram descritas em relação à área total dos estabelecimentos, em hectares (AE) ou em equivalente homem ${ }^{2}(\mathrm{EH})$.

Grupo 1 - Nível Tecnológico TE1 - percentual dos estabelecimentos que utilizaram assistência técnica; TE2 - percentual dos estabelecimentos que utilizaram adubos e corretivos; TE3 - número de tratores (unidades)/AE; TE4 - número de tratores (unidades)/EH; e TE5 - proporção da área com pastagens plantadas, em hectares.

Grupo 2 - Tamanho T1 - área utilizada para o cultivo de lavouras permanentes (em ha)/AE; T2 - área utilizada para o cultivo de lavouras temporárias (em ha)/AE; T3 - área destinada a pastagens plantadas (em ha)/AE; T4 - total de bovinos (cabeças)/AE; T5 - total de suínos (cabeças)/EH; e $\mathrm{T} 6$ - total de galinhas, galos, frangas, frangos e pintos (cabeças)/EH.

Grupo 3 - Modernização e Capitalização M1 - valor dos investimentos (em reais)/AE; M2 - valor dos financiamentos obtidos (em reais)/AE; M3 valor dos adubos e corretivos utilizados pelos estabelecimentos agropecuários (em reais)/AE; M4 - valor dos agrotóxicos utilizados pelos estabelecimentos agropecuários (em reais)/AE; e M5 - valor da energia elétrica e combustíveis gastos pelos estabelecimentos agropecuários (em reais)/AE.

Grupo 4 - Meio ambiente A1 - proporção dos estabelecimentos que utilizaram o plantio em nível; A2 - proporção dos estabelecimentos que utilizaram terraços; e A3 - proporção da área dos estabelecimentos coberta com matas.

Grupo 5 - Produtividade Parcial dos Fatores P1 - valor da produção vegetal, em R\$/AE; P2 - valor da produção vegetal, em R\$/EH; P3 - valor da produção animal, em R $\$ / A E ; ~ P 4$ - valor da produção animal, em $\mathrm{R} \$ / \mathrm{EH}$; P5 - litros de leite de vaca (em mil litros)/vacas ordenhadas no ano (cabeças); e P6 - quantidade produzida de ovos de galinhas no ano nos estabelecimentos agropecuários (dúzias)/número de cabeças de galinhas (cabeças).

As variáveis organizadas no grupo "nível tecnológico" buscam captar a disponibilidade de máquinas e equipamentos nos estabelecimentos agropecuários bem como a capacidade dos produtores em usá-los corretamente. Assumese também que um produtor que apresente uma maior área com pastagens plantadas em detrimento da área total de pastagens também apresente um nível tecnológico maior. Essas variáveis buscam captar o que Hayami \& Ruttan (1998) chamaram de tecnologia mecânica e biológica.

\footnotetext{
${ }^{2} \mathrm{O}$ valor em equivalente homem foi calculado por meio do somatório dos trabalhadores maiores de 14 anos envolvidos na produção agropecuária, nos respectivos períodos, sendo a mão de obra feminina ponderada por 0,8 .
} 
O grupo "tamanho" compreende variáveis relacionadas à escala e especialização dos estabelecimentos produtivos, tanto em razão da área do estabelecimento como da mão de obra usada. Uma maior especialização permite uma maior mecanização em razão das características específicas de muitas tecnologias, ademais, conforme Hayami \& Ruttan (1998), uma maior mecanização envolve o cultivo de áreas maiores. A teoria microeconômica ressalta ainda que o aumento da área de cultivo pode levar a ganhos na economia de escala, mediante redução nos custos, a partir da utilização mais intensiva de insumos como máquinas, mão de obra etc. (Ferguson 1995). Portanto, na escolha da tecnologia a ser adotada, a área total explorada pela cultura pode ser uma importante variável explicativa.

A "modernização e capitalização" envolve aquelas variáveis relacionadas a tecnologias químicas além daquelas relacionadas à capacidade das propriedades de capitalizar e reinvestir na atividade. Além disso, as variáveis relacionadas às tecnologias químicas foram consideradas como relacionadas à capacidade de capitalização das empresas rurais em razão na necessidade de capital de giro para que esses insumos pudessem ser adquiridos, em detrimento das tecnologias mecânicas e biológicas que não necessitam ser, obrigatoriamente, adquiridas a cada período ${ }^{3}$. Schumpeter (1985) corrobora essa ideia ao destacar que quando o empresário utiliza o próprio capital na produção de determinado bem, o lucro obtido pela venda desse bem é acrescentado ao capital, já convertido em meios de produção, promovendo a capitalização do empresário e estimulando-o a conceber novas combinações tecnológicas na busca do aumento do lucro. Dessa forma, o risco de adoção de novas tecnologias diminui quando o empresário utiliza o próprio capital.

As variáveis inseridas no grupo "meio ambiente" captam a direção da adoção tecnológica e da modernização em relação à conservação (ou não) dos recursos naturais. No presente estudo, pela restrição de variáveis, essa variável capta a direção da modernização na conservação do solo.

Por fim, no grupo "produtividade", estão inseridas aquelas variáveis relacionadas à produtividade parcial da terra, do trabalho e alguns fatores produtivos. Esse grupo será mantido como suplementar à análise, i.e., esse grupo será projetado sobre os eixos fatoriais, uma vez que a produtividade dos fatores pode ser considerada como consequência das características dos grupos 1 a 4. Esse procedimento foi adotado em vários trabalhos, como o de Kageyama \& Leone (2002). Além disso, a distribuição das variáveis nos grupos considerou a correlação entre elas.

\subsection{Análise de Agrupamentos}

Tomando os escores fatoriais estimados por meio da análise fatorial múltipla, os agrupamentos foram construídos utilizando a análise de agrupamentos ou clusters como forma de determinar quais as tecnologias produtivas utilizadas nas diferentes microrregiões do estado. Além disso, a utilização dos escores fatoriais garante a ausência de colinearidade entre as variáveis e evita que variáveis colineares recebam maior peso na construção dos clusters (Hair et al. 1995).

\footnotetext{
${ }^{3}$ A análise da correlação indicou essa relação, por exemplo, a correlação de M3 e M4 com M1 foi de 0,68 e 0,50, respectivamente, sendo que ambas foram estatisticamente significativas ao nível de $1 \%$
} 
Os clusters foram formados por meio do método de dois estágios proposto por Punj \& Stewart (1983). Primeiramente, o número de grupos é determinado utilizando o método de variância mínima de Wald e a estatística Tquadrado proposta por Duda \& Hart (1973). Posteriormente, essa informação é utilizada na distribuição dos produtores entre os grupos por meio do método de média $\mathrm{k}(k \text { mean })^{4}$.

\section{Resultados e discussão}

A tabela 1 apresenta as estatísticas descritivas das variáveis utilizadas na AFM, com valores médios e coeficiente de variação para cada ano, bem como a variação da média das variáveis entre os dois anos de análise, tomando 1995/96 como base.

Observa-se que há um forte aumento da produtividade parcial vegetal nos estabelecimentos agropecuários (P1 e $\mathrm{P} 2)$, principalmente quanto à área. $\mathrm{O}$ menor ganho de produtividade da mão de obra pode ser explicado pelo número de pessoas empregadas na agropecuária ter aumentado de 25767 para 26006 (em equivalente homem), enquanto a área utilizada na produção dos estabelecimentos agropecuários diminuiu de 618358 para 494659 hectares e o número de estabelecimentos aumentou de 7525 para 8357. Para a produtividade animal, apenas a produção láctea apresentou crescimento, enquanto que as demais variáveis para produtividade animal não apresentou variação estatisticamente significativa entre os períodos analisados. Destaca-se que a interpretação quanto às mudanças nessas variáveis deve ser feita com cuidado, dado a alteração no período de coleta do Censo Agropecuário.

Analisando as variáveis relacionadas à tecnologia empregada, pode-se observar uma melhoria quanto ao uso de assistência técnica pelos estabelecimentos agropecuários e no percentual de pastagens plantadas, que aumentou 35\%. As demais variáveis não apresentaram diferenças estatisticamente significativas.

Quanto ao tamanho das áreas destinadas a cada atividade ou distribuição das atividades, o número de bovinos por hectare apresentou substancial crescimento, seguido do cultivo de lavouras permanentes e pastagens plantadas. Por outro lado, a área com lavouras temporárias, o número de suínos e aves por equivalente homem não apresentou diferença significativa entre os períodos estudados.

As variáveis do grupo de modernização indicam uma elevação significativa do investimento, financiamento, uso de adubos e agrotóxicos e energia elétrica. O aumento do investimento e financiamento por hectare pode ter contribuído à elevação do número de tratores (TE3 e TE4), à substituição de pastagens naturais por plantadas (TE5) e ao próprio uso de adubos e agrotóxicos (M3 e M4) que culminaram no aumento da produtividade vegetal e animal.

Essa tendência de aumento da mecanização, considerando o uso de agrotóxicos, adubos e energia elétrica, também está associada à maior intensidade de capital, que ajuda a explicar a substancial elevação da produtividade vegetal e a melhora da produtividade parcial apenas na produção de leite, estatisticamente. A produção vegetal pode ter intensificado o uso do capital, enquanto a produção animal elevou o uso da mão de obra, que pode ser associado ao tipo

\footnotetext{
${ }^{4}$ Mais detalhes da análise de agrupamentos (cluster) podem ser vistos em Hair et al. (1995).
} 
Tabela 1: Estatística descritiva das variáveis, microrregiões de Minas Gerais, 1995/96 e 2006

\begin{tabular}{|c|c|c|c|c|c|}
\hline \multirow{2}{*}{ Variáveis } & \multicolumn{2}{|c|}{ Ano 1995/1996 } & \multicolumn{2}{|c|}{ Ano 2006} & \multirow{2}{*}{ Variação da média } \\
\hline & Média & $\begin{array}{l}\text { Coeficiente de } \\
\text { Variação }^{c}\end{array}$ & Média & $\begin{array}{l}\text { Coeficiente de } \\
\text { Variação }^{c}\end{array}$ & \\
\hline $\mathrm{P} 1^{* * *}$ & 209,39 & 0,92 & 549,74 & 1,50 & $163 \%$ \\
\hline$P 2^{* * * *}$ & 3921,74 & 0,82 & 7580,07 & 1,33 & $93 \%$ \\
\hline$P 3^{\text {ns }}$ & 159,54 & 0,70 & 187,19 & 1,06 & $17 \%$ \\
\hline $\mathrm{P} 4^{\mathrm{ns}}$ & 3372,6 & 0,75 & 2843,24 & 0,92 & $-16 \%$ \\
\hline $\mathrm{P} 5^{* * *}$ & 0,46 & 1,26 & 1,65 & 0,33 & $260 \%$ \\
\hline$P 6^{\mathrm{ns}}$ & 6,93 & 2,25 & 4,65 & 2,67 & $-33 \%$ \\
\hline $\mathrm{TE} 1^{* *}$ & 0,27 & 0,67 & 0,29 & 0,52 & $6 \%$ \\
\hline TE $2^{\text {ns }}$ & 0,64 & 0,39 & 0,66 & 0,48 & $4 \%$ \\
\hline $\mathrm{TE} 3^{\mathrm{ns}}$ & 2,7 & 0,93 & 3,4 & 0,91 & $24 \%$ \\
\hline $\mathrm{TE} 4^{\mathrm{ns}}$ & 0,06 & 0,83 & 0,06 & 1,00 & $10 \%$ \\
\hline $\mathrm{TE} 5^{* * *}$ & 0,4 & 0,43 & 0,54 & 0,26 & $35 \%$ \\
\hline $\mathrm{T} 1^{* *}$ & 0,04 & 1,50 & 0,07 & 1,14 & $70 \%$ \\
\hline $\mathrm{T} 2^{\mathrm{ns}}$ & 0,08 & 0,50 & 0,08 & 0,75 & $-4 \%$ \\
\hline $\mathrm{T} 3^{* *}$ & 0,25 & 0,48 & 0,3 & 0,33 & $20 \%$ \\
\hline $\mathrm{T} 4^{* * *}$ & 0,82 & 1,33 & 1,77 & 0,47 & $116 \%$ \\
\hline $\mathrm{T} 5^{\mathrm{ns}}$ & 1,96 & 1,16 & 2,37 & 1,46 & $21 \%$ \\
\hline $\mathrm{T}^{\mathrm{ns}}$ & 93,37 & 3,83 & 143,2 & 4,24 & $53 \%$ \\
\hline$M 1^{* * *}$ & 7,87 & 1,15 & 62,99 & 1,02 & $700 \%$ \\
\hline$M 2^{* * *}$ & 32,69 & 0,57 & 99,28 & 0,55 & $204 \%$ \\
\hline$M 3^{* * *}$ & 14,77 & 1,49 & 83,77 & 1,15 & $467 \%$ \\
\hline$M 4^{* *}$ & 4,66 & 1,61 & 32,12 & 3,27 & $589 \%$ \\
\hline $\mathrm{M} 5^{* *}$ & 10,63 & 1,08 & 104,58 & 3,75 & $884 \%$ \\
\hline $\mathrm{A} 1^{\mathrm{ns}}$ & 0,45 & 3,16 & 0,33 & 0,45 & $-27 \%$ \\
\hline $\mathrm{A} 2^{* *}$ & 0,08 & 2,25 & 0,03 & 1,00 & $-59 \%$ \\
\hline $\mathrm{A} 3^{* * *}$ & 0,17 & 0,65 & 0,04 & 1,50 & $-79 \%$ \\
\hline
\end{tabular}

Fonte: Resultados da Pesquisa.

${ }^{a}$ Notas: P1 - valor da produção vegetal em R \$AE; P2 - valor da produção vegetal em $\mathrm{R}$ \$ EH; P3 - valor da produção animal em R \$/AE; P4 - valor da produção animal em $\mathrm{R} \$ / \mathrm{EH} ; \mathrm{P} 5$ - litros de leite de vaca (em mil litros) /vacas ordenhadas no ano (cabeças); P6 - quantidade produzida de ovos de galinhas no ano nos estabelecimentos agropecuários (dúzias)/número de cabeças de galinhas (cabeças); TE1 - percentual dos estabelecimentos que utilizam assistência técnica; TE2 - percentual dos estabelecimentos que utilizam adubos e corretivos; TE3 - número de tratores (unidades) /AE (mil hectares); TE4 - número de tratores (unidades) /EH; TE5 proporção da área com pastagens que é plantada em hectares; T1 — área utilizada para o cultivo de lavouras permanentes (em ha)/AE;T2 - área utilizada para o cultivo de lavouras temporárias (em ha) / AE; T3 - área destinada a pastagens plantadas (em ha)/AE; T4 - total de bovinos (cabeças) /AE; T5 — total de suínos (cabeças) /EH; T6 total de galinhas, galos, frangas, frangos e pintos (cabeças)/EH; M1 — valor dos investimentos (reais)/AE; M2 — valor dos financiamentos obtidos (reais)/AE; M3 valor dos adubos e corretivos utilizados pelos estabelecimentos agropecuários (em ha)/AE; M4 - valor dos agrotóxicos utilizados pelos estabelecimentos agropecuários (em R\$) /AE; M5 — valor de energia elétrica e combustíveis gastos pelos estabelecimentos agropecuários(em R\$)/AE; A1 — proporção dos estabelecimentos que utilizam o plantio em nível; A2 - proporção dos estabelecimentos que utilizam terraços; e A3 - proporção da área dos estabelecimentos coberta com matas.

${ }^{b}$ As estatísticas descritivas refere-se às 66 microrregiões de Minas Gerais para cada ano.

${ }^{c}$ Coeficiente de variação = desvio padrão / média.

${ }^{d}$ Os símbolos ${ }^{* * *} \mathrm{e}^{* *}$ indicam que a diferença das médias entre os anos de estudo foram significativas diferentes ao nível de significância de $1 \%$ e $5 \%$, respectivamente, e ns indica que a diferença das médias não foi estatisticamente significativa pelo teste t-student ao nível de significância de $10 \%$. 
de sistema de produção pecuário mineiro. Esse comportamento pode indicar, como apresentado anteriormente, o caráter não uniforme de ganhos agropecuários, o que implica que regiões de maior pecuária podem ter apresentado uma elevação nos custos, em relação às de maior intensidade agrícola.

Por outro lado, essa melhoria dos investimentos e produtividade não foi acompanhada da melhoria das práticas de conservação ambiental, uma vez que a utilização do plantio de nível diminuiu no período, enquanto a utilização de terraços e a área coberta de matas não apresentou diferença significativa entre os períodos analisados. Essa tendência pode comprometer a capacidade produtiva do solo e elevar os custos. Destaca-se que esse comportamento pode indicar problemas futuros, entretanto, o aumento na área de lavouras permanentes pode ser um atenuante uma vez que há menor revolvimento do solo. Todavia, a área ocupada com lavouras permanentes representou apenas 8\% da área dos estabelecimentos em 2006.

Assim, a observação das estatísticas descritivas indica ganhos de produtividade, principalmente vegetal, melhoria na tecnologia empregada e aumento das culturas permanentes e pastagens plantadas com redução ou estabilização na adoção das práticas de conservação do solo e na área de matas. Esse comportamento pode diferir entre as culturas, como as estatísticas indicaram, e, por conseguinte, entre regiões.

A análise por variável, e analisando as variações entre regiões, pode ser não conclusiva. Dessa forma, a análise fatorial múltipla permite agrupar essas variáveis, de forma que o comportamento do grupo de variáveis e das regiões segue examinado pela análise de cluster, que permite verificar regiões de comportamento semelhantes, tornando a análise factível.

Então, inicialmente foram estimados os escores fatoriais para os grupos de variáveis. A qualidade do ajustamento foi analisada, e os fatores foram interpretados quanto às características captadas pelos fatores extraídos. Posteriormente, utilizando os fatores extraídos, foram calculadas suas variações percentuais; as microrregiões foram classificadas quanto a essas variações ou trajetórias em quatro grupos. A AFM foi calculada por meio do software R, versão 2.12.2 utilizando o pacote de análise FactoMineR (Lê et al. 2008) e a análise de agrupamentos foi feita por meio do programa Stata 11.

\subsection{Interpretação dos fatores comuns}

A análise fatorial foi executada com os dados empilhados, de forma a agregar os indicadores em um número menor de variáveis e permitir a comparação das trajetórias da produção agropecuária entre as microrregiões para os períodos de estudo. Dessa forma, a Análise Fatorial Múltipla extraiu três fatores com raiz característica maior do que 1 (Tabela 2).

Tabela 2: Autovalores e variância acumulada dos componentes

\begin{tabular}{cccc}
\hline Fatores & Autovalor & Variância (\%) & Variância Acumulada (\%) \\
\hline 1 & 2,108 & 25,106 & 25,106 \\
2 & 1,287 & 15,332 & 40,438 \\
3 & 1,135 & 13,524 & 53,963 \\
\hline
\end{tabular}

Fonte: Resultados da Pesquisa. 
A análise dos três primeiros fatores (Tabela 2) do grupo de variáveis indica que estes foram responsáveis pela maior porcentagem da variabilidade acumulada $(53,96 \%)$. O primeiro autovalor $(2,10)$ indica que o primeiro fator da análise global corresponde a uma direção importante para o conjunto do grupo de variáveis, assim como para cada um deles isoladamente, uma vez que cada fator apresentou autovalor maior do que 1, ou seja, cada fator explica pelo menos sua própria variância. Além disso, foram considerados na análise apenas os fatores que apresentassem autovalor maio do que $1^{5}$.

Além disso, como forma de analisar a adequabilidade dos dados à análise fatorial, foram calculados a Medida de adequação da amostra proposta por Kaiser (1974) e o teste T de esferacidade de Bartlett (1951). A medida de adequação assume valores entre 0 e 1 , sendo 1 perfeita adequação, sendo que o menor valor aceitável é 0,5 (Hair et al. 1995). O valor calculado foi de 0,67. A estatística $T$ apresenta distribuição qui-quadrado e apresenta hipótese nula de que a matriz de correlação é uma matriz identidade. $O$ valor calculado foi $\chi_{171 g l}^{2}=1738,31$, estatisticamente significativo a $1 \%$. Esses testes indicaram a adequação dos dados ao método.

A Tabela 3 apresenta as relações entre os fatores globais e os grupos de variáveis. As coordenadas tomam valores entre 0 e 1 e são resultado da projeção da inércia de cada grupo sobre as inércias globais. A importância de cada grupo de variáveis em cada eixo é dada pelas coordenadas e contribuições de cada grupo. Os cossenos ao quadrado indicam quão bem o comportamento dos grupos de variáveis foi captado por um dado eixo, e o valor máximo possível é 1 .

Os resultados indicam que todos os grupos ativos contribuíram significativamente para a inércia total do primeiro eixo, destacando-se os indicadores de tecnologia e modernização, ao passo que, para a inércia total do segundo eixo, destacou-se o indicador de tamanho (grupo 2), com 55,47\% de contribuição.

Os elevados cossenos ao quadrado sugerem que os indicadores de tecnologia e modernização estão bem representados no primeiro eixo, enquanto o indicador de tamanho está mais bem representado no segundo e o indicador ambiental está bem representado no terceiro eixo, contribuindo com $56,21 \%$ para a inércia total, com elevado cosseno ao quadrado $(0,3235)$.

Por meio da Tabela 3, pode-se observar que os grupos de variáveis têm o mesmo peso relativo, dado pelo inverso do número de grupos ativos. As distâncias à origem são interpretadas como indicador de multidimensionalidade; assim, valores para a distância iguais ou próximos a 1 indicam que as variáveis se comportam como uma dimensão, o que ocorreu para os grupos de variáveis ativas, que possuem valores entre 1,20 e 2,24.

\footnotetext{
${ }^{5}$ Destaca-se que ao contrário da análise fatorial clássica, o somatório dos autovalores na análise fatorial múltipla, normalmente, não será igual ao número de variáveis. Isso ocorre em virtude da divisão das variáveis de cada grupo pelo respectivo valor singular. Ilustrativamente, isso pode ser percebido pela redução da variância, por exemplo, a variável TE1, em que $\operatorname{Var}(\mathrm{TE} 5)=0,028$. O primeiro valor singular para esse grupo, calculado no primeiro estágio foi de 1,67. Então $\operatorname{Var}(T E 5 / 1,67)=(1 / 1,67)^{2} * \operatorname{Var}(T E 5)=0,010$. Assim, como a variância de cada componente é igual ao eigenvalue e como a variância total das variáveis é igual à variação total dos componentes principais, a divisão das variáveis reduz a variância e, por conseguinte, os eigenvalues, de forma que o somatório dos eigenvalues não será igual ao número de variáveis. Ademais, segundo Abdi et al. (2013), a divisão das variáveis de cada grupo pelo primeiro valor singular permite normalizar todas as variáveis, de forma que o primeiro componente de cada tabela de dados seja igual a 1 , garantindo que nenhuma tabela de dados domine a variância da primeira dimensão.
} 


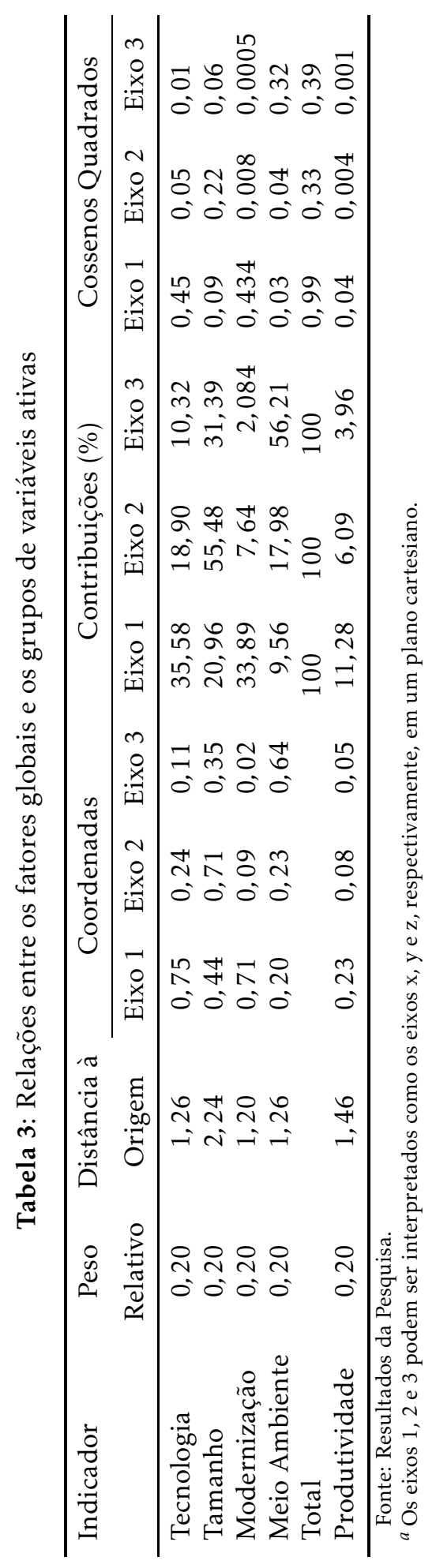


De modo geral, o eixo 1 (ou dimensão 1) captou o efeito simultâneo dos aspectos relativos à tecnologia e modernização; o segundo, a escala de operação das atividades produtivas agropecuárias (dimensão 2); e o terceiro, a utilização de práticas de conservação pelos produtores rurais.

Complementando a análise, a Figura 1 representa a posição dos quatro grupos ativos e do grupo suplementar em um plano tridimensional, utilizando os valores das coordenadas dos grupos eixo 1, eixo 2 e eixo 3. A coordenada de um grupo sobre o eixo é a inércia (variância) acumulada das variáveis do grupo sobre o eixo comum da AFM. O gráfico ponto-grupo deve ser interpretado como a projeção ortogonal de uma nuvem de pontos sobre o eixo comum.

Os pontos próximos (Figura 1) indicam que as estruturas definidas pelas variáveis são semelhantes. Dessa forma, semelhanças foram observadas apenas entre as estruturas "modernização" e "tecnologia". As estruturas de conservação do meio ambiente, produtividade e tamanho não apresentaram semelhanças, no período de 1996 a 2006. Esse comportamento não era esperado, uma vez que se acreditava que a melhoria da tecnologia, da modernização e/ou das práticas de conservação do meio ambiente apresentasse efeito positivo sobre a produtividade; assim, essas estruturas estariam intercorrelacionadas, muito embora esse comportamento já fosse indicado pelas estatísticas descritivas (Tabela 1).

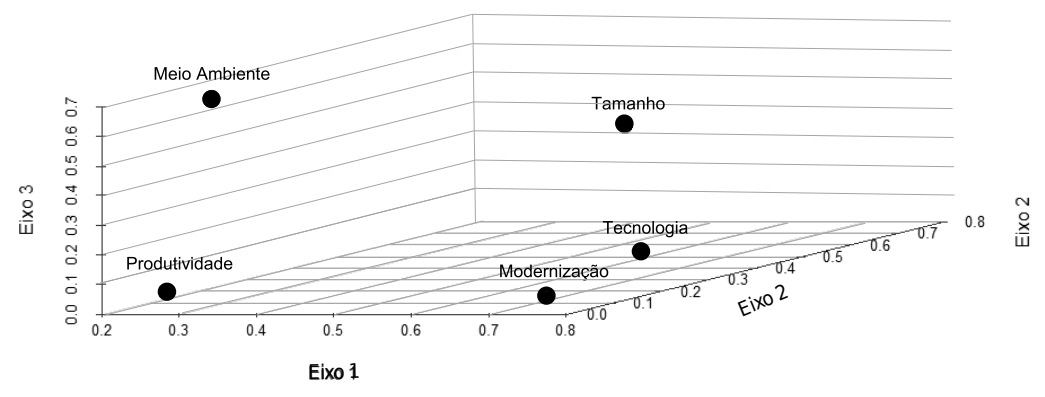

Fonte: Resultados da Pesquisa.

Figura 1: Coordenadas dos grupos de variáveis associadas à trajetória de modernização no primeiro plano da AFM.

Essa ausência de relação indica que as práticas agrícolas adotadas pelos estabelecimentos não são adequadas ou não estão sendo executadas de maneira correta ou que a tecnologia adotada pelos estabelecimentos não é adequada. Entretanto, essa não relação de tecnologia, modernização e produtividade com a dimensão "meio ambiente" pode ser decorrente do modelo tecnológico da Revolução Verde, apoiado no uso intensivo de insumos mecânicos, biológicos e químicos, que resultam em inúmeros impactos ambientais indesejáveis (Albergoni \& Pelaz 2007).

Para analisar a semelhança entre as projeções das quatro nuvens parciais (grupos ativos) sobre um mesmo eixo global, Kageyama \& Leone (2002) sugerem que se calculem os coeficientes de correlação entre os fatores parciais dessas projeções e os fatores da nuvem global (Tabela 4). O primeiro eixo apresenta semelhança com os indicadores de tecnologia, tamanho e modernização, destacados em negrito, com menor associação ao indicador ambiental. O eixo 
2 traduz com maior importância o tamanho da produção, e o terceiro eixo capta o caráter ambiental.

Tabela 4: Correlação para os dois primeiros eixos da AFM, entre as projeções de nuvem global e as três nuvens parciais

\begin{tabular}{lclc}
\hline & Eixo 1 & \multicolumn{1}{c}{ Eixo 2 } & Eixo 3 \\
\hline Tecnologia & 0,872716 & 0,641371 & 0,429244 \\
Tamanho & 0,869422 & 0,89504 & 0,747411 \\
Modernização & 0,847668 & 0,316975 & 0,160345 \\
Meio Ambiente & 0,629397 & 0,482043 & 0,799517 \\
\hline
\end{tabular}

Fonte: Resultados da Pesquisa.

A Tabela 5 apresenta as coordenadas de cada variável em relação aos três primeiros eixos fatoriais da AFM, bem como a comunalidade (proporção da variância das variáveis explicadas pelos fatores extraídos, que nesse estudo foram três). As variáveis com maiores valores para as coordenadas e contribuições relativas à variância total dos eixos foram destacadas em negrito e consideradas na interpretação de cada eixo.

O primeiro eixo será denominado "tecnologia e modernização", como apresentado anteriormente nas Tabelas 3 e 5 e na Figura 1, estando diretamente relacionado à produção vegetal e indiretamente à produção animal (uma vez que a produção vegetal pode ser utilizada na alimentação do rebanho). As principais variáveis responsáveis pela formação do primeiro eixo, considerando as variáveis com maiores coordenadas e contribuições para a inércia total (variância) desse eixo, foram: TE1 - proporção dos estabelecimentos que utilizam assistência técnica (importante para a difusão da tecnologia e, consequentemente, para a modernização dos estabelecimentos agropecuários); TE2 - proporção dos estabelecimentos que utilizam adubos e corretivos; TE3 - número de tratores (unidades)/AE; TE4 - número de tratores (unidades)/EH; T1 - área utilizada para o cultivo de lavouras permanentes (em ha)/AE; T2 - área utilizada para o cultivo de lavouras temporárias (em hectares)/AE; M1 - valor dos investimentos (em reais)/AE; M2 - valor dos financiamentos obtidos (em reais)/AE; M3- valor dos adubos e corretivos utilizados pelos estabelecimentos agropecuários (em reais)/AE; M4 - valor dos agrotóxicos utilizados pelos estabelecimentos agropecuários (em reais)/AE; e A3 - proporção da área dos estabelecimentos com área coberta com matas.

Quanto à correlação negativa entre A3 e o eixo 1 (tecnologia e modernização), afere-se que a elevação da tecnologia e da modernização nos estabelecimentos (com imobilização de capitais em máquinas e equipamentos) eleva o custo de oportunidade para as áreas não trabalhadas, ocupadas com matas e florestas, já que representam uma perda para o produtor pela receita não gerada com produtos agropecuários e também pelo capital investido, como apresentado por Bacha (2005).

O segundo eixo será denominado "produção animal", por ser formado, principalmente, por variáveis relacionadas à escala e à produção animal. As principais variáveis responsáveis pela sua formação foram: TE5 - proporção da área com pastagens plantadas, em hectares; T3 - área destinada a pastagens plantadas (em ha)/AE; T1 - área utilizada para o cultivo de lavouras perma- 
nentes (em ha)/AE, sendo que essa variável tem relação inversa ao eixo, uma vez que as lavouras permanentes competem por área com a produção animal; T5 - total de suínos (cabeças)/EH; e T6 - total de galinhas, galos, frangas, frangos e pintos (em cabeças)/EH.

O terceiro eixo será denominado "práticas de conservação", por estar mais relacionado, considerando as coordenadas e as contribuições, a variáveis que expressam esse comportamento, além de estar associado à produção pecuária. As principais variáveis responsáveis por sua formação foram: T3 - área destinada a pastagens plantadas (em ha)/AE; T4 - total de bovinos (cabeças)/AE; A1 - proporção dos estabelecimentos que utilizam o plantio em nível; e A2 proporção dos estabelecimentos que utilizam terraços.

Salienta-se que as variáveis presentes nesse fator estão associadas ao menor revolvimento do solo e outras práticas, que foram consideradas como capazes de reduzir a erosão do solo. Entretanto, destaca-se a limitação de variáveis que permitam uma melhor representação da conservação ambiental nos estabelecimentos agropecuários, considerando a poluição das águas, do solo, do ar e outras variáveis. Nesse sentido, a pecuária poderia apresentar um fator degradante pela poluição, principalmente a pecuária leiteira, dos cursos de água pelos dejetos, por exemplo.

Destaca-se que, observando a coluna que retrata a comunalidade, a variável que retrata o consumo de energia elétrica não se relacionou a nenhum dos fatores. Além disso, a retirada dessa variável não modificou as estatísticas, entretanto, optou-se por mantê-la por razão teórica, conforme apresentado na justificativa das variáveis. A variável T6 também apresentou baixa comunalidade, entretanto, essa apresentou contribuição importante para o segundo eixo.

\subsection{Trajetórias de modernização agropecuária das microrregiões mineiras}

As microrregiões mineiras foram agrupadas tendo como referência a variação dos escores fatoriais entre os períodos de análise, calculados por meio da Análise Fatorial Múltipla. A análise de clusters foi, então, utilizada para identificação das trajetórias de modernização, do nível tecnológico, da escala e tamanho dos estabelecimentos e das práticas ambientais de conservação adotadas nos estabelecimentos agropecuários no período de 1996 a 2006. Os clusters foram formados por meio do método de dois estágios, proposto por Punj \& Stewart (1983), determinando primeiramente o número de grupos por meio do método de variância mínima de Wald; posteriormente, essa informação será utilizada na segunda etapa, para a formação dos grupos por meio do método de média $\mathrm{k}$.

O método de variância mínima de Wald sinalizou que quatro grupos melhor representariam os grupos homogêneos. Uma vez determinado o número de grupos a serem formados (quatro), utilizou-se o método de média k para determinar quais microrregiões deveriam ser enquadradas em cada grupo homogêneo, sendo que cada grupo foi considerado como apresentando uma dada trajetória. A Figura 2 apresenta as microrregiões por grupos formados; os limites das macrorregiões estão destacados pela linha mais escura, como, por exemplo, a região Noroeste, que compreende a microrregião de Unaí e Paracatu. 
Tabela 5: Coordenadas e contribuições das variáveis ativas no primeiro plano fatorial

\begin{tabular}{|c|c|c|c|c|c|c|c|c|}
\hline \multirow[t]{2}{*}{ Grupo } & \multirow[t]{2}{*}{ Variáveis } & \multicolumn{3}{|c|}{ Coordenadas } & \multicolumn{3}{|c|}{ Contribuições (\%) } & \multirow[t]{2}{*}{ Comunidade } \\
\hline & & Eixo 1 & Eixo 2 & Eixo 3 & Eixo 1 & Eixo 2 & Eixo 3 & \\
\hline \multirow{5}{*}{1} & TE1 & 0,69 & 0,33 & $-0,19$ & 7,97 & 3,11 & 1,16 & 0,62 \\
\hline & TE2 & 0,71 & $-0,18$ & 0,05 & 8,59 & 0,95 & 0,09 & 0,54 \\
\hline & TE3 & 0,81 & $-0,13$ & 0,06 & 11,11 & 0,47 & 0,10 & 0,68 \\
\hline & TE4 & 0,6 & 0,48 & $-0,37$ & 6,19 & 6,27 & 4,38 & 0,73 \\
\hline & TE5 & 0,32 & 0,54 & $-0,38$ & 1,73 & 8,10 & 4,58 & 0,54 \\
\hline \multirow{6}{*}{2} & $\mathrm{~T} 1$ & 0,6 & $-0,58$ & 0,26 & 9,19 & 14,24 & 3,26 & 0,76 \\
\hline & $\mathrm{T} 2$ & 0,52 & 0,17 & $-0,14$ & 7,10 & 1,17 & 1,01 & 0,32 \\
\hline & T3 & 0,31 & 0,58 & $-0,48$ & 2,57 & 14,24 & 11,09 & 0,66 \\
\hline & $\mathrm{T} 4$ & 0,13 & 0,19 & 0,58 & 0,46 & 1,50 & 5,94 & 0,39 \\
\hline & T5 & 0,23 & 0,62 & 0,04 & 1,36 & 16,40 & 0,09 & 0,44 \\
\hline & T6 & 0,1 & 0,43 & 0,01 & 0,28 & 7,93 & 0,01 & 0,20 \\
\hline \multirow{5}{*}{3} & M1 & 0,78 & $-0,27$ & 0,09 & 10,35 & 2,00 & 0,25 & 0,69 \\
\hline & M2 & 0,77 & $-0,28$ & 0,1 & 10,12 & 2,09 & 0,31 & 0,68 \\
\hline & M3 & 0,71 & $-0,23$ & 0,15 & 8,49 & 1,43 & 0,67 & 0,58 \\
\hline & M4 & 0,5 & $-0,27$ & 0,16 & 4,26 & 2,06 & 0,83 & 0,35 \\
\hline & M5 & 0,2 & $-0,05$ & 0,02 & 0,66 & 0,06 & 0,02 & 0,04 \\
\hline \multirow{3}{*}{4} & A1 & 0,11 & 0,46 & 0,8 & 0,30 & 8,43 & 29,06 & 0,86 \\
\hline & A2 & 0,05 & 0,49 & 0,75 & 0,06 & 9,46 & 25,85 & 0,81 \\
\hline & A3 & $-0,61$ & 0,05 & 0,17 & 9,20 & 0,09 & 1,31 & 0,40 \\
\hline
\end{tabular}

Fonte: Resultados da Pesquisa.

${ }^{a} \mathrm{P} 1$ - valor da produção vegetal em R \$/AE; P2 — valor da produção vegetal em R\$/EH; P3 - valor da produção animal em R\$/AE; P4 — valor da produção animal em R \$EH; P5 - litros de leite de vaca (em mil litros) /vacas ordenhadas no ano (cabeças); P6 - quantidade produzida de ovos de galinhas no ano nos estabelecimentos agropecuários (dúzias)/número de cabeças de galinhas (cabeças); TE1 - percentual dos estabelecimentos que utilizam assistência técnica; TE2 - percentual dos estabelecimentos que utilizam adubos e corretivos; TE3 - número de tratores (unidades) /AE (mil hectares); TE4 - número de tratores (unidades) /EH; TE5 — proporção da área com pastagens que é plantada em hectares; T1 — área utilizada para o cultivo de lavouras permanentes (em ha)/AE;T2 - área utilizada para o cultivo de lavouras temporárias (em ha) /AE; T3 - área destinada a pastagens plantadas (em ha)/AE; T4 - total de bovinos (cabeças) /AE; T5 total de suínos (cabeças) /EH; T6 - total de galinhas, galos, frangas, frangos e pintos (cabeças)/EH; M1 — valor dos investimentos (reais)/AE; M2 - valor dos financiamentos obtidos (reais)/AE; M3 - valor dos adubos e corretivos utilizados pelos estabelecimentos agropecuários (em ha)/AE; M4 — valor dos agrotóxicos utilizados pelos estabelecimentos agropecuários (em R\$) /AE; M5 - valor de energia elétrica e combustíveis gastos pelos estabelecimentos agropecuários(em R\$)/AE; A1 — proporção dos estabelecimentos que utilizam o plantio em nível; A2 - proporção dos estabelecimentos que utilizam terraços; e A3 - proporção da área dos estabelecimentos coberta com matas.

${ }^{b}$ Também foram calculadas as coordenadas (ou correlações entre as variáveis e os eixos) e a comunalidade pela análise fatorial "clássica". Os resultados calculados apresentaram um pior ajustamento geral aos eixos. As variáveis T2, T4, T5 e T6, apresentaram pior ajustamento, com comunalidade de 0,28, 0,22, 0,26 e 0,08 , respectivamente. Todos os resultados podem ser obtidos junto aos autores. 


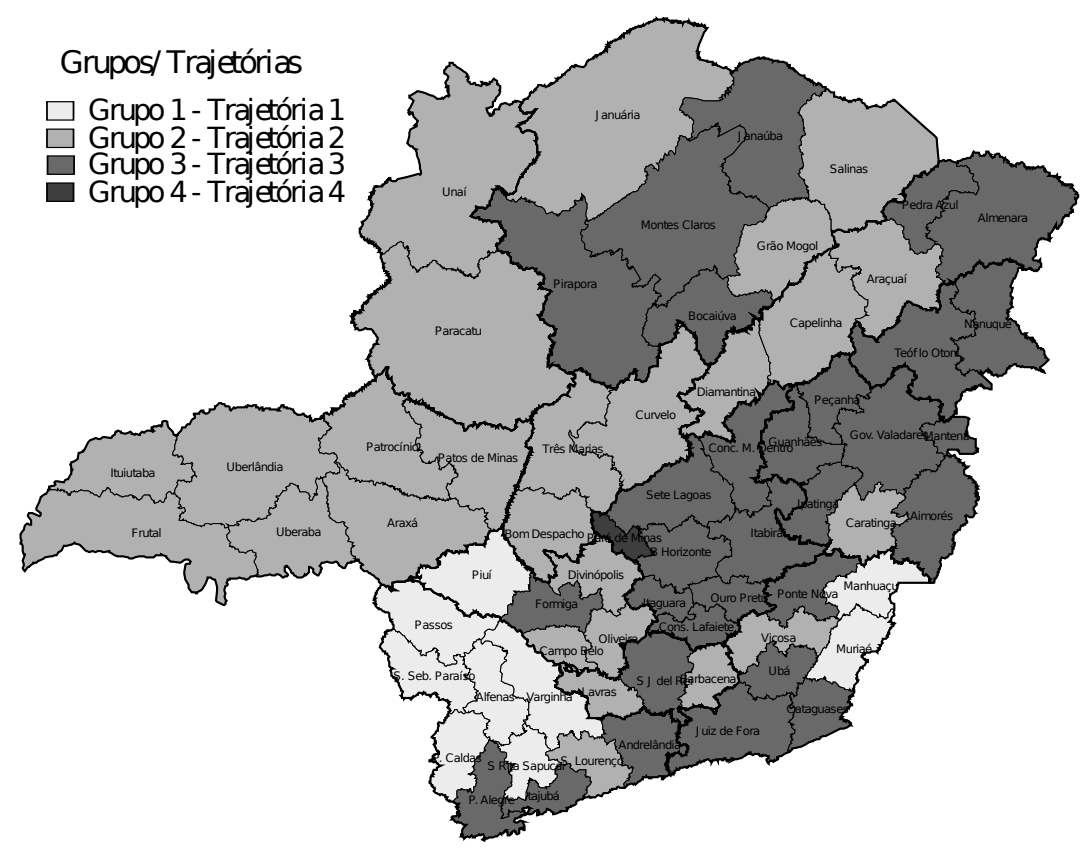

Fonte: Resultados da Pesquisa.

Figura 2: Microrregiões mineiras por grupos formados

Cada grupo de microrregiões compreende uma trajetória de modernização, ou seja, regiões pertencentes a um mesmo grupo compartilham comportamento semelhante na evolução das características analisadas e refletidas nos escores fatoriais como tecnologia e modernização, produção animal e utilização de práticas de conservação ambiental.

A Tabela 6 apresenta os valores médios de variação dos escores fatoriais entre os períodos de 1995/96 e 2006 por trajetórias. Os valores positivos indicam aumento, e os valores negativos, redução dos escores fatoriais entre períodos de análise.

Tabela 6: Trajetórias da produção agropecuária das microrregiões mineiras entre 1996 e 2006

\begin{tabular}{lcccc}
\hline Trajetórias & $\begin{array}{c}\text { Número de } \\
\text { Microrregiões }\end{array}$ & $\Delta$ Fator 1 $(\%)$ & $\Delta$ Fator 2 $(\%)$ & $\Delta$ Fator 3 $(\%)$ \\
\hline Trajetória 1 & 9 & 2,5378 & $-1,2419$ & 0,9168 \\
Trajetória 2 & 26 & 1,3275 & 0,0586 & 0,5541 \\
Trajetória 3 & 30 & 0,8506 & 0,0846 & $-0,5432$ \\
Trajetória 4 & 1 & 0,8951 & $-1,625$ & $-9,4618$ \\
Média & 66 & 1,2692 & $-0,1323$ & $-0,0469$ \\
\hline
\end{tabular}

Fonte: Resultados da Pesquisa.

Nota: O fator 1 capta mudanças na tecnologia e modernização; o fator 2, a trajetória da produção animal no período considerado; e o fator 3, mudanças nas práticas de conservação do meio ambiente adotadas pelos produtores rurais.

De maneira geral (Tabela 6), o Estado de Minas Gerais apresentou aumento na tecnologia empregada e redução da produção animal e da utilização de práticas de conservação ambiental, além de apresentar crescimento da produtivi- 
dade parcial agrícola, tanto em área como em mão de obra, e elevação tímida e/ou queda da produtividade parcial da pecuária.

As trajetórias foram descritas e interpretadas em termos das variações dos fatores extraídos pela Análise Fatorial Múltipla e da variação na produtividade da terra e do trabalho das microrregiões de Minas Gerais entre 1996 e 2006 (Tabelas 6 e 7). Importante destacar que as trajetórias foram descritas em termos das variações dos três fatores considerados.

A Figura 3 representa as microrregiões mineiras, considerando apenas variações do primeiro fator (tecnologia e modernização), uma vez que este apresenta maior importância para a variabilidade total dos dados.

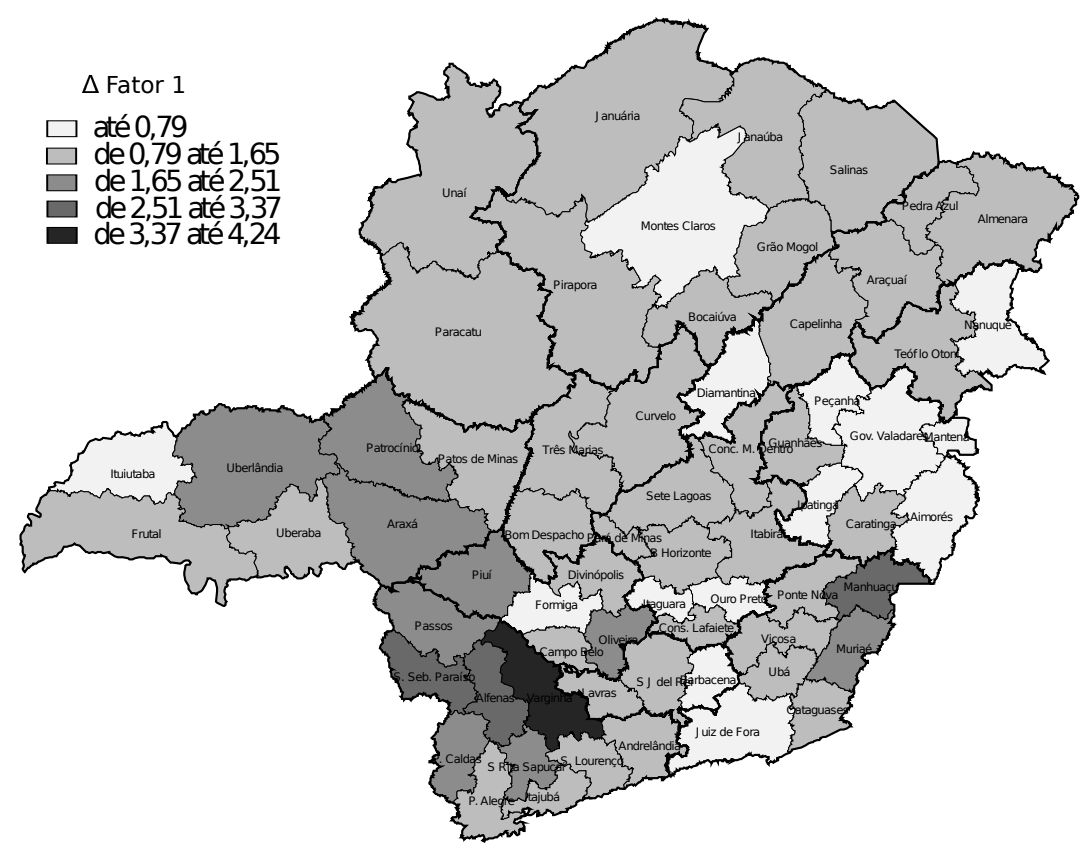

Fonte: Resultados da Pesquisa.

Figura 3: Microrregiões mineiras quanto a intervalos do fator 1.

Por meio da Figura 3, percebe-se que a maior parte das microrregiões mineiras apresentou pequenos ganhos de modernização e tecnologia, excetuando apenas algumas microrregiões do Sul e Triângulo/Alto Paranaíba. Esse comportamento pode ser explicado por meio de três justificativas: as regiões de maior desenvolvimento cresceram proporcionalmente pouco, dada a base anterior elevada; algumas regiões evoluíram pouco, pela reduzida capacidade dos estabelecimentos em absorver novas tecnologias, como a região Norte, com altos nível de pobreza, o que representa um grave problema; e algumas regiões que se destacaram quanto à evolução na tecnologia e modernização apresentavam baixo nível anterior e foram influenciadas pelo dinamismo das regiões de fronteira brasileira, como o Triângulo Mineiro.

Considerando as informações das Tabelas 6 e 7, a primeira trajetória caracteriza-se pela maior elevação do fator 1 , isto é, da tecnologia e modernização; queda considerável do fator 2, produção animal; e elevação do fator 3, sendo que nove microrregiões mineiras enquadram-se nessa trajetória. Ela apresenta ganhos de produtividade animal acima da média e elevação da produtividade 
vegetal abaixo da média (Tabela 7).

Analisando o comportamento das microrregiões desse grupo, pode-se aferir que as microrregiões que apresentam esse comportamento quanto à trajetória de produção agropecuária, por vocação ou por características gerenciais e pessoais dos produtores, destacaram-se pelo crescimento da pecuária tecnificada. Esse comportamento é atribuído por BDMG (2002) às regiões do sul do Estado, sendo essa a maior proporção de regiões nesse grupo. Espera-se, dessa forma, maior capitalização dos estabelecimentos e capacidade gerencial dos produtores, o que permitiria a estes utilizar novas tecnologias de maneira eficiente, obtendo ganhos de produtividade.

A elevação da adoção de práticas de conservação do solo pode ser explicada pelo relevo acidentado, em conjunto com o caráter empresarial dos estabelecimentos e o nível de informação e capitalização, o que permite o conhecimento, por parte dos produtores, da importância das práticas de conservação ambiental.

A trajetória 2 é caracterizada por elevação da tecnologia e modernização (fator 1), pequena elevação da produção animal (fator 2) e elevação das práticas de conservação adotadas pelos produtores rurais (fator 3 ) acima da média (Tabela 6), porém, com desempenho mediano quanto à produtividade parcial vegetal e animal por área e mão de obra (Tabela 7). O desempenho abaixo da média ou queda da produtividade por ser atribuído à base, ou seja, é reconhecido que as regiões do Triângulo Mineiro e Noroeste de Minas apresentam alto nível tecnológico e alta produtividade da terra e do trabalho agropecuário. Esses ganhos podem ser atribuídos ao relevo da região, à utilização de manejos adequados e práticas modernas, que proporcionaram ganhos de produção com ganhos ambientais, e à seleção genética (Carneiro \& Fontes 2005).

Dessa forma, esse comportamento pode indicar redução das taxas de crescimento e/ou depreciação do capital dessas regiões. Por outro lado, algumas regiões, como Jequitinhonha, são reconhecidas pelo baixo nível tecnológico e dinamismo, com a menor taxa de utilização de assistência técnica, controle de pragas e doenças, uso de adubos e corretivos, etc. (IBGE 2010a). O baixo crescimento nessa região pode ser creditado a fatores estruturais, como baixo nível de capital, agricultura de subsistência e baixa integração ao mercado, como tratado por BDMG (2002), o que destaca a necessidade da ação governamental para dinamizar essas regiões. A baixa produtividade das regiões pobres do Estado também pode ser explicada pelo acesso à saúde, educação e nutrição, uma vez que, como Lipton (2001) destaca, esses fatores são fortes determinantes da produtividade em regiões mais pobres.

A trajetória 3 englobou 30 microrregiões, com elevação da tecnologia e modernização abaixo da média, pequena elevação da pecuária, mas acima da média, e queda da utilização das práticas de conservação pelos estabelecimentos, além de crescimento acima da média para a produtividade parcial vegetal e animal. Essa trajetória compreende as microrregiões do Norte de Minas, Zona da Mata, Vale do Mucuri, Belo Horizonte e Vale do Rio Doce.

No caso das microrregiões que apresentaram a produção agropecuária caracterizada pela terceira trajetória, com aumentos das dimensões modernização e pecuária, isso pode ser atribuído ao histórico das regiões. A principal característica dessas regiões é a importância da pecuária. Para a região do Vale do Rio Doce, por exemplo, o maior incentivo dado à pecuária tornou a agricultura pouco expressiva. O aumento da importância da pecuária também pode ser atribuído à aptidão agrícola dessas regiões. Segundo Carneiro \& 
Fontes (2005), elas não apresentariam boa aptidão para o cultivo de lavouras, sendo adequadas para formação de pastagens.

A trajetória 4 engloba apenas a microrregião de Pará de Minas, que apresentou os maiores ganhos para a produtividade parcial vegetal e os piores ganhos para a produtividade parcial animal, bem como, de maneira geral (Tabela 7), os piores ganhos quanto à tecnologia, modernização, pecuária e adoção de práticas de conservação (fatores 1, 2 e 3). A queda da produtividade animal pode ser explicada pela queda do fator 2. A queda expressiva das práticas de conservação pode estar associada à competição por recursos e à pouca necessidade de práticas de plantio em nível e terraços nesta microrregião.

\section{Conclusões}

Investigar as trajetórias dos sistemas produtivos é de vital importância para o entendimento do desenvolvimento econômico regional. Essa afirmativa é válida especialmente no desenvolvimento de Estados que têm na agropecuária um dos pilares da sua economia, como Minas Gerais. Nesse sentido, o presente trabalho se propôs a analisar as trajetórias tecnológicas agropecuárias das microrregiões mineiras entre os anos de 1996 e 2006.

A análise dos grupos de variáveis indicou que "modernização" e "tecnologia" estavam relacionadas entre si, mas não à conservação do meio ambiente, e à produtividade e ao tamanho dos estabelecimentos. Esse comportamento indica que uma maior modernização e tecnologia não implicam em maior conservação ambiental, produtividade ou tamanho dos estabelecimentos, sendo neutra a esses, o que pode indicar a não adequabilidade, uma vez que um dos objetivos são os ganhos de produtividade.

Os resultados deste estudo identificaram quatro trajetórias da produção agropecuária no Estado quanto a modernização e tecnologia, capitalização, adoção de práticas de conservação do meio ambiente e produtividade das microrregiões. A análise indicou que a grande maioria das microrregiões (85\%) apresentou ganhos de tecnologia e modernização, mas em magnitudes diferentes, muito embora a adoção de práticas de conservação tenha reduzido em sua maioria.

O comportamento da pecuária foi divergente entre as regiões, em algumas foi acompanhado de ganhos de produtividade, em outras apresentou queda da produção e/ou produtividade.

Além disso, as microrregiões de baixa modernização e padrão tecnológico apresentaram reduzida capacidade de os estabelecimentos absorverem e fazerem uso efetivo dessas novas tecnologias. Esse deve ser fator motivador da ação governamental para o treinamento dos produtores quanto a essas novas tecnologias, principalmente nas regiões mais pobres de Minas Gerais, que apresentam baixo nível educacional, como, por exemplo, a microrregião do Jequitinhonha.

A relação negativa ou conflitante entre a manutenção de matas para a conservação do solo e recursos hídricos e a adoção de novas tecnologias e modernização das microrregiões merece um estudo aprofundado, embora ela possa ser inicialmente explicada pelo custo de oportunidade do capital investido em tecnologias. Espera-se que a melhoria tecnológica permita o melhor aproveitamento de áreas cultivadas pelos estabelecimentos. 


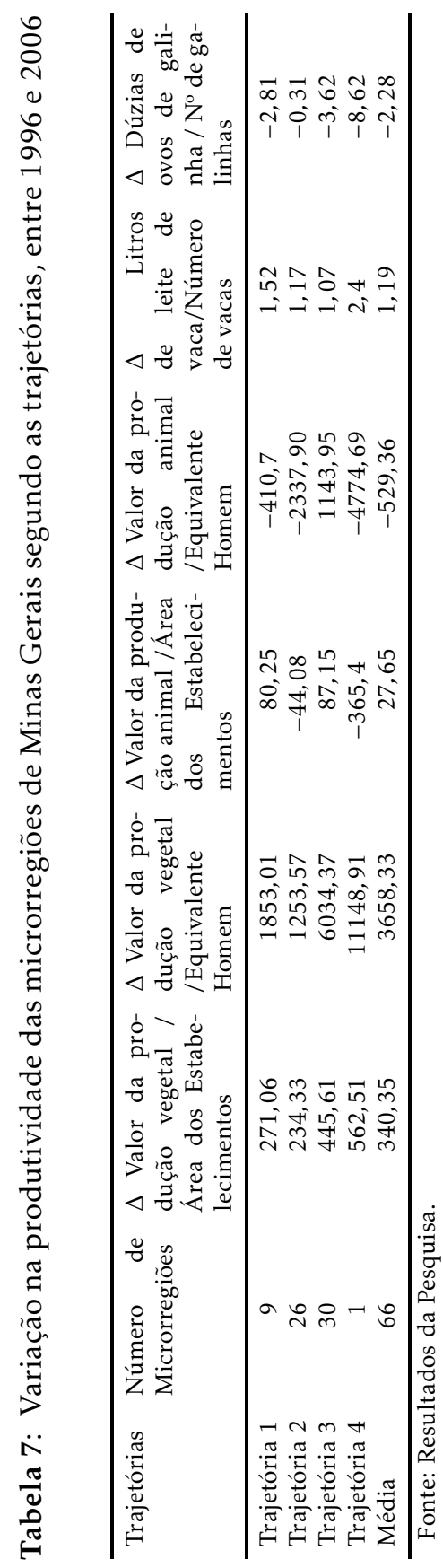




\section{Referências Bibliográficas}

Abdi, H., Williams, L. \& Valentin, D. (2013), 'Multiple factor analysis: principal component analysis for multitable and multiblock data sets', WIREs Computational Statatistics 5(2), 149-179.

Albergoni, L. \& Pelaz, V. (2007), 'Da revolução verde à agrobiotecnologia: ruptura ou continuidade de paradigmas?', Revista de Economia 33(1), 31-53.

Bacha, C. (2005), 'Eficácia da política de reserva legal no brasil', Teoria e Evidência Econômica 13(25), 9-27.

Bartlett, M. (1951), 'The effect of standardization on a $x 2$ approximation in factor analysis', Biometrica 38(3-4), 337-344.

BDMG, B. d. D. d. M. G. (2002), Minas Gerais do Século XXI, Vol. 4, Rona Editora, Belo Horizonte.

Carneiro, P. \& Fontes, M. (2005), Aspectos geográficos e agrícolas do estado de minas gerais, in R. Fontes \& M. Fontes, eds, 'Crescimento e desigualdade regional em Minas Gerais', Folha de Viçosa Ltda, pp. 151 - 222.

Cruz, A. (2007), Composição do agronegócio no estado de minas gerais, Mestrado em economia aplicada, Universidade Federal de Viçosa, Viçosa, MG.

Duda, R. \& Hart, P. (1973), Pattern classification and scene analysis, Wiley, New York.

Escofier, B. \& Pagès, J. (1984), L'analyse factorielle multiple: une méthode de comparaison de groupes de variables, in S. R.R., D. E., E. Y., L. L. \& J. Pagès, eds, 'Data Analysis and Informatics III', North-Holland, pp. 4-55.

Ferguson, C. (1995), Microeconomia, 15a ed. edn, Forense Universitária, Rio de Janeiro.

Ferreira Júnior, S., Baptista, A. \& Lima, J. (2004), 'A modernização agropecuária nas microrregiões do estado de minas gerais', Revista de Economia e Sociologia Rural 42(1), 73-89.

FGV, F. G. V. (2010), 'Índice geral de preços'.

URL: $h t t p: / / p o r t a l i b r e . f g v . b r$

Freitas, C., Bacha, C. \& Fossatti, D. (2004), 'Análise do crescimento desigual do setor agropecuário brasileiro em termos de produtos e estados, período 1970 a 2000', XLII Congresso Brasileiro de Economia e Sociologia Rural, Cuiabá, Mato Grosso.

Gasques, J., Bastos, E., Bacchi, M. \& Valdes, C. (2010), 'Produtividade total dos fatores e transformações da agricultura brasileira: análise dos dados dos censos agropecuários', $48^{\circ}$ Congresso da Sociedade Brasileira de Economia, Administração e Sociologia Rural, Campo Grande, Mato Grosso do Sul.

Hair, J., Anderson, R., Tatham, R. \& Black, W. (1995), Multivariate Data Analysis: with readings, Prentice Hall, New Jersey.

Hayami, Y. \& Ruttan, V. (1998), Desenvolvimento agrícola: Teoria e experiências internacionais, Embrapa, Brasília. 
Helfand, S. \& Resende, G. (2001), 'Brazilian agriculture in the 1990s: Impact of the policy reforms.', Instituto de Pesquisa Econômica Aplicada, Rio de Janeiro.

IBGE, I. B. d. G. e. E. (2010a), 'Censo agropecuário 2006'.

URL: $h t t p: / / w w w . s i d r a . i b g e . g o v . b r$

IBGE, I. B. d. G. e. E. (2010b), 'Censo agropecuário 1995/1996’.

URL: http://www.sidra.ibge.gov.br

Kageyama, A. \& Leone, E. (2002), 'Trajetória da modernização e emprego agrícola no brasil, 1985 - 1996', Revista de Economia e Sociologia Rural $40(1), 9-28$.

Kaiser, H. (1974), 'An index of factorial simplicity', Psychometrika 39(1), 3126.

Lipton, M. (2001), 'Rural poverty reduction: the neglected priority', International Fund for Agricultural Development's Report on Rural Poverty.

Llanillo, R., Grossi, M., Santos, F., Munhos, P. \& Guimarães, M. (2006), 'Regionalização da agricultura do estado do paraná, brasil', Ciência Rural 36(1), 120-127.

Lê, S., Josse, J. \& Husson, F. (2008), 'Factominer: An r package for multivariate analysis', Journal of Statistical Software 25(1), 1-18.

Meyer, L. (1997), Modernização da agricultura e desenvolvimento sustentado: o caso de minas gerais - 1970 a 1985, Mestrado em economia aplicada, Universidade Federal de Viçosa, Viçosa, MG.

Meyer, L. \& Braga, M. (1998), 'O crescimento das desigualdades tecnológicas na agricultura mineira', Revista de Economia e Sociologia Rural 36(2), 59-90.

Punj, G. \& Stewart, D. (1983), 'Cluster analysis in marketing research: review and suggestions for application', Journal of Marketing Research 20(2), 134148.

Schumpeter, J. (1985), A teoria do desenvolvimento econômico, Nova Cultural, São Paulo.

Silva, H., Rosa, C., Resende, A. \& Simões, R. (2008), 'Agropecuária e urbanização: Uma análise multivariada para minas gerais, 1995-2000', Revista Econômica do Nordeste 39(2), 285-305.

Souza, P. \& Lima, J. (2003), 'Intensidade e dinâmica da modernização agrícola no brasil e nas unidades da federação', Revista Brasileira de Economia 57(4), 795-824. 